\title{
LA ACTIVIDAD LEGISLATIVA DE LOS PARLAMENTOS DE CATALUÑA Y EL PAIS VASCO AL FINAL DE SU PRIMERA LEGISLATURA (1980-1984)
}

\author{
POR \\ JOAN SUBIRATS \\ Universidad de Barcelona
}

\begin{abstract}
«Ninguna cosa hace tanto honor a un Príncipe tecientemente elevado como las nuevas leyes, las nuevas institucionés imaginadas por él. Cuando están formadas sobre buenos fundamentos y tienen alguna grandeza en sí mismas, le hacen digno de respeto y admiración»
\end{abstract}

(Maquiavelo, El Príncipe).

Como ha afirmado un eminente jurista, «la opción política del constituyente por un Estado de autonomías territoriales, opción adoptada y resuelta sin demasiada conciencia de las implicaciones estructurales que ello impone, nos ha introducido de golpe en una situación sumamente problemática, que constituye, sin duda, a mi juicio, el mayor reto con que se ha encontrado nuestro Estado desde el fin del Antiguo Régimen, marcado por la invasión napoleónica» ${ }^{1}$. La Constitución de 1978 intentó solventar, con su artículo 2. y el título VIII, uno de los más constantes y recurrentes problemas de nuestra historia moderna y contemporánea, y que más esperanzas había suscitado durante la transición a la democracia. Pretendieron así los constituyentes articular institucional y políticamente en un sistema coherente, pero abierto y flexible, las distintas lenguas, culturas y tradiciones: que constituyen lo que, hasta entonces, se había eufemísticamente denominado «peculiaridades regionales».

Desde el punto de vista institucional y jurídico, lo realmente importante es que se dotaba a esa teórica autonomía política de capacidad normativa, es decir, se facultaba a las Comunidades Autónomas para que redactaran y aprobaran sus propias leyes.

La Disposición transitoria segunda de nuestra Carta Fundamental posibilitó que Cataluña y el País Vasco iniciaran su proceso autonómico antes que otras

1 E. García de Enterría, «Estudio preliminar», en La distribución de competencias económicas entre el poder central y las autonomias territoriales en el Derecho comparado $y$ en la Constitución española, Madrid, Instituto de Estudios Económicos, 1980, pág. 13. 
Comunidades, y hoy (enero de 1984) podemos hablar de «experiencia autonómica» al referinos a casi cuatro años de autogobierno catalán y vasco.

Este artículo no pretende ofrecer un balance global y definitivo de lo que ha sido la actividad legislativa de los Parlamentos vasco y catalán en estos casi cuatro años. Lo que se intenta es presentar a los interesados una aproximación a ese balance, introduciendo algunas hipótesis explicativas y avanzando una cierta perspectiva.

1. Como se ha señalado acertadamente ${ }^{2}$, las Comunidades Autónomas vendrían definidas como sujetos que gozan de un verdadero poder y de una genuina dirección política en el ámbito de determinadas materias enunciadas en la Constitución y concretadas en el correspondiente Estatuto de Autonomía. Ello se plasma en la capacidad legislativa de que gozan las Comunidades Autónomas, ya que, en su defecto, nos encontraríamos en un supuesto de simple descentralización administrativa.

La Constitución y el Estatuto de Autonomía son los dos textos básicos que delimitan el quantum del poder efectivo de la Generalidad y de la Comunidad Autónoma vasca, ya que fijan un sistema de competencias y señalan en qué materias puede legislar el respectivo Parlamento.

Este sistema era coherente con la decisión política tomada por los constituyentes: un sistema de autonomías flexible, con diversas vías de acceso y diversos ritmos en el tiempo, en el que no se especificaba ni el mapa autonómico, pero en el que se posibilitaba que, aunque los puntos y momentos de salida fuesen distintos, se pudiese alcanzar con el tiempo un mismo nivel competencial. Era, y es, un sistema abierto, que favorece la integración en el sistema autonómico de comunidades con distintos grados de sensibilidad y voluntad de autogobierno, pero que, al mismo tiempo, se presta también a muchas ambigüedades y equívocos.

2. Dejando, por el momento, a un lado esa problemática, que constituye de alguna manera el marco general de esta reflexión, veamos cómo se ha concretado esa capacidad de autogobierno en las Comunidades vasca y catalana.

El Parlamento de Cataluña ha aprobado en estos casi cuatro años (desde abril de 1980 hasta enero de 1984) un total de 61 leyes. De entre ellas cabría destacar ante todo las de contenido más claramente institucional: la ley del Parlamento, del Presidente y del Consejo Ejecutivo (más conocida como Estatuto Interior), la ley Reguladora del Consejo Consultivo y la ley de Transferencia Urgente y Plena de las Diputaciones a la Generalidad, que, como es sabido, fue casi totalmente anulada por el Tribunal Constitucional. Otras especialmente importante por su repercusión social son la ley de Normalización Lingüística o la de creación de la Corporación Catalana de Radio y Televisión (TV-3), y por su ámbito material de aplicación, un conjunto de leyes administrativas en materia de urbanismo y protección del medio ambiente y de espacios naturales, entre las que destaca la ley de Protección de la Legalidad Urbanística y la de Política Territorial. Señalemos también la existencia de otras

$2 \mathrm{~J}$. Salas, «Els poders normatius de la Generalitat de Catalunya», en Lectures de l'Estatut d'Autonomía de Catalunya Taula de Canvi, Barcelona, mayo 1980. 
leyes de diverso carácter e incidencia práctica, pero de indudable relevancia: la ley de Bibliotecas, la ley de Fundaciones Privadas, la ley de Colegios Profesionales y la ley de Cooperativas. Finalmente cabe tener en cuenta que de las 61 leyes aprobadas, las de aprobación de Presupuestos, ùlteriores ampliaciones de crédito, modificaciones presupuestas o dotaciones suman un total de 16.

En el mismo período de tiempo, el Parlamento vasco ha aprobado un total de 60 leyes, de las cuales 24 (un 40 por 100) son presupuestarias o de aprobación de gastos, ampliaciones de crédito, etc. De entre las restantes cabe destacar la ley de Gobierno, similar al Estatuto Interior catalán, y la que regula las relaciones entre las Instituciones Comunes y los Territorios Históricos, que después de casi tres años de polémica en el PNV fue, finalmente, aprobada a finales de noviembre de 1983. También son significativas: la que regula el uso del euskera, la nueva ley Electoral, la de Cooperativas, la de Contratación de Cargas, la de creación del Ente Radio Televisión Vasca, entre otras. Recientemente, el Parlamento ha aprobado una ley por la que se autorizaba al gobierno a emitir decretos-leyes ante la gravísima situación planteada por las recientes inundaciones en el País Vasco. En virtud de esa ley, el gobièrno emitió, y el Parlamento convalidó, cinco decretos-leyes, que hemos incluido en el cómputo total. Otras leyes son claramente autoorganizativas, así: ley de Sedes, Designación de Senadores, Sustitución de Parlamentarios Vascos, y tres que regulan la elección de las respectivas Juntas Generales de los Territorios Históricos.

$\mathrm{Si}$ examinamos los respectivos Estatutos y vemos las competencias sobre las que, teóricamente, pueden legislar ambos Parlamentos, observaremos cómo en ambos casos el balance de su producción legislativa en estos casi cuatro años no es muy amplio. Se han hecho bastantes leyes, pero muchas de ellas son estrictamente autoorganizativas o institucionales, o, por otro lado, se limitan a aprobar presupuestos, ampliar créditos o. autorizar gastos. De hecho, después de una primera experiencia traumática, entendiéndose el varapalo del Tribunal Constitucional a la ley catalana de Transferencia de las Diputaciones, o a la vasca de Inviolabilidad e Inmunidad de los Parlamentarios, parece como si se hubiera preferido dirigir los esfuerzos legislativos más hacia los aspectos fundacionales o de gestión que no hacia los de una mayor enjundia material, sin duda más generadores de conflictos.

En este sentido es ilustrativa la lectura de los programas legislativos de los gobiernos de Convergencia i Unió o del PNV al iniciarse la primera Legislatura autonómica y su comparación con las leyes finalmente aprobadas.

3. Las dos Comunidades, sin embargo, han conseguido un elevado nivel de gestión, tanto por los fondos presupuestarios que manejan como por el número de funcionarios a su servicio.

La Generalidad de Cataluña aprobó su primer Presupuesto en 1979, durante la etapa de preautonomía del presidente Tarradellas, con un volumen de 925 millones. El Presupuesto de 1980, primero del gobierno Pujol, fue de 6.791 millones, y ha llegado en la actualidad a los 319.800 millones. En cuanto al número de funcionarios, la evolución ha sido la siguiente: 1.507 en 1979 , 1967 al año siguiente, 35.390 en 1981, para estabilizarse desde 1982 alrededor de los 75.000 funcionarios. De hecho, dejando a un lado pocos, pero signi- 
ficativos traspasos aún pendientes (INEM, Aguas, Universidades, etc.), la Generalidad de Cataluña ha llegado casi al 100 por 100 de los trapasos previstos estatutariamente.

En el País Vasco las cifras son menos contundentes, tanto por su menor entidad demográfica y territorial como por la peculiar organización derivada de su tradición foralista. Las Diputaciones Provinciales han mantenido buena parte de sus prerrogativas anteriores, y gozan de saneados presupuestos derivados de la estructura del Conciero Económico. A partir de la aprobación de la polémica ley de Territorios Históricos esa situación se institucionalizará, incrementándose las competencias de los organismos forales, Diputaciones y Juntas Generales y creándose un Consejo Vasco de Finanzas Públicas que decidirá la cuantía de los fondos que los Territorios Históricos destinan a sufragar los gastos comunes, que pasarán al Gobierno vasco, y los dedicados a pagar el cupo destinado al Estado.

Los primeros Presupuestos de la Comunidad Autónoma vasca datan de 1981 y tuvieron una cuantía de 43.000 millones. Los Presupuestos para 1984 tienen prevista una cuantía de 131.278 millones. El número de funcionarios propios de la Comunidad, sin incluir los que dependen de las Diputaciones, ronda los 17.000 . El nivel de traspasos es plenamente comparable al ya mencionado para Cataluña.

4. De esta panorámica se desprende un cierto desajuste entre nivel de traspasos alcanzado, capacidad presupuestaria y volumen de la Administración propia y la entidad de la producción legislativa. El objetivo esencial de este trabajo es formular algunas hipótesis explicativas de ese desajuste, hipótesis que pueden derivarse tanto de factores internos a la propia Comunidad como de factores externos a la misma.

Un primer elemento a considerar es el que puede derivarse de la mencionada confusión sobre el concepto y significación de las llamadas «competencias exclusivas». El criterio adoptado en el texto constitucional, al que ya hemos aludido, conllevaba que fueran los diferentes Estatutos de Autonomía los que precisaran y delimitaran el marco competencial dibujado en la Constitución. Jordi Solé Tura afirma que, en Cataluña, se siguió una técnica cuyo principio fundamental «era lo que yo llamaría sacar el 'negativo' de la Constitución» ${ }^{3}$. Así se atribuían a la Generalidad, como competencias exclusivas, aquellas materias que el artículo 149 no atribuía exclusivamente al Estado. Pero este modelo, que se siguió en general con posterioridad por el resto de autonomías, incluyendo el País Vasco, introducía algunas fórmulas circulares que se multiplicaron en la negociación con el Gobierno central.

Al ponerse en marcha las autonomías de Cataluña y del País Vasco empezaron los problemas. Los primeros conflictos surgieron ante leyes aprobadas por los respectivos Parlamentos que, o bien eran difícilmente encajables en el marco autonómico, caso de la ley de Inviolabilidad o Inmunidad de los Parlamentarios Vascos, o bien tenían graves deficiencias técnicas, caso de la ley de Transferencia Urgente de las Diputaciones Catalanas. Esa primera conflictivi-

${ }^{3}$ J. Solé Tura, «La jurisprudencia del Tribunal Constitucional y el Estado de las autonomías», art. a aparecer próximamente, Barcelona, 1983, pág. 4 del original. 
dad; los hechos del 23 de febrero, que proyectaron su sombra en el proceso autonómico, y una posición global de recelo de la Administración central ante los primeros pasos del Estado autonómico condujeron a la creación de la «Comisión de Expertos», a los Acuerdos autonómicos entre UCD y PS,OE y, en definitiva, al proyecto de la LOAPA. Se escogía, pues, una vía distinta de la planteada por los constituyentes. Se trataba de «reconducir y racionalizar» el proceso autonómico a través de una ley general que fijaba criterios para delimitar competencias, postulaba la prevalencia del derecho estatal en el supuesto de colisión, establecía cómo debía interpretarse la Constitución y significaba de hecho la negación de un ámbito exclusivo propio de las Comunidades Autónomas. La sentencia del Tribunal Constitucional ante los recursos previos presentados desde distintas instituciones y fuerzas políticas ha cerrado esa posibilidad, esa implícita reforma constitucional planteada en la LOAPA, y ha vuelto a establecer el camino de la construcción del Estado de las Autonomías en «el juego de los diversos componentes del bloque de constitucionalidad, en el protagonismo de las instituciones autonómicas, en la negoc̣iación política y en la decisión última del Tribunal Constitucional como instancia arbitral y definitoria de los ámbitos funcionales de la autonomía» ${ }^{4}$.

En efecto, el Tribunal Constitucional había recordado en varias sentencias el «sentido marcadamente equívoco con que el adjetivo exclusivo se utiliza tanto en el texto de la Constitución como en el de los Estatutos de Autonomía», y así en su jurisprudencia iba negando carácter excluyente y monopolizador a ese adjetivo, delimitando materia por materia los diversos átnbitos competenciales del Estado y de la Comunidad Autónoma implicada en ẹl conflicto. Esa vía, que huía de calificaciones genéricas, quería ser superada por el tratamiento globalizador de la LOAPA. Después de la sentencia 76/1983, de 5 de agosto, queda claro que sólo de la vía del conflicto de competencia ante el alto Tribunal puede surgir la delimitación de la titularidad en cada materia concreta y en relación con el caso controvertido.

Es ésta una vía compleja y que de alguna manera presupone el conflicto, pero ello ha sido y es normal en todo Estado Federal o de autonomías regionales y además resulta la única vía respetuosa con el vigente texto constitucional. Desde la perspectiva de las Comunidades Autónomas, esta situación no permite una actuación a la ligera en materia legislativa, ya que una reiteración de sentencias negativas implicaría un indudable desgaste político. Pero es evidente también que sólo después de haber legislado sobre determinada materia y no haberse planteado ningún conflicto de competencia, o, en caso de conflicto, después de la reafirmación del Tribunal Constitucional sobre la plena capacidad del Parlamento autonómico para dictar normas sobre esa materia, se estará seguro de la titularidad sobre la misma.

Ultimamente están planteándose por parte de los Gobiernos vasco y catalán conflictos positivos de competencias ante disposiciones normativas del Gobierno central. De esa manera se utiliza una vía cautelar para que sea el Tribunal Constitucional quien, con su sentencia, señale a quién corresponde la titularidad de la competencia en litigio, y, en caso de resolverse a favor de

4 J. Solé Tura, op. cit., pág. 8. 
la Comunidad Autónoma litigante, ésta podrá posteriormente legislar con una cierta seguridad.

Otro argumento esgrimido para justificar en algunos casos la falta de producción legislativa de los Parlamentos vasco y catalán ha sido el no cumplimiento de los traspasos o la falta de legislación de bases del Estado que permita una posterior legislación de desarrollo por parte de la Comunidad Autónoma. De hecho, la distinción entre función y servicio, entre materia objeto de la competencia comunitaria y órganos y bienes ya creados por el Estado en la materia en cuestión (distinción ya clarificada por la doctrina) permite afirmar que las Comunidades Autónomas pueden ejercer sus competencias en aquellas materias que les hayan sido atribuidas por los respectivos Estatutos, y ello aunque los servicios (la organización) continúe temporalmente en manos del Estado. En nuestro sistema constitucional, la competencia, único requisito exigible desde esta perspectiva para ejercitar legítimamente la potestad legislativa, viene atribuida directa $\mathrm{e}$ inmediatament por los respectivos Estatutos de Autonomía de las CC. AA. y no por los decretos de transferencias de bienes y servicios ${ }^{5}$. A pesar de ello, hasta ahora se ha esperado a tener traspasados los bienes y servicios para ejercer la competencia legislativa.

En Cataluña sólo se inició una vez el proceso legislativo sobre una materia antes de su efectivo traspaso, y fue en relación al tema de las Entidades Profesionales Agrarias; pero los distintos planteamientos políticos, a los que más adelante se alude, impidieron por dos veces que el proyecto del Gobierno siguiera adelante. El otro caso planteado, la falta de legislación básica del Estado, tampoco parece que sea un impedimento absoluto para la legislación autonómica. Como ya ha precisado el Tribunal Constitucional, las CC. AA. pueden adoptar leyes de detalle sin que se requiera la existencia previa de una ley estatal habilitadora. De hecho, así ha sido, y buen ejemplo de ello son la ley de Transferencia Urgente de las Diputaciones o la ley de Medidas Urgentes sobre la Función Pública de la Generalidad, aunque ambas hayan sido objeto de recurso ante el Tribunal Constitucional. Lo único que ha recomendado el Tribunal es prudencia en esa legislación que antecede a la básica del Estado. Ese camino no está, pues, cerrado, y la Comunidad puede legislar tomando como referencia la legislación vigente y la propia Constitución. Ahora bien, es evidente que en algunos casos (Tribunal Superior de Justicia, Régimen Local, Función Pública) no resulta fácil ejercer esa potestad antes de que sean definitivamente aprobadas las leyes estatales previstas.

Otro elemento que normalmente se baraja en el ámbito general que se analiza es el uso del recurso de inconstitucionalidad por parte de los gobiernos de UCD y del PSOE ante la legislación de los Parlamentos vasco y catalán. Del total de 121 leyes aprobadas por ambos Parlamentos hasta enero de 1984, 25 han sido objeto, hasta ahora, de recurso de inconstituconalidad por parte del Gobierno central. Doce leyes del Parlamento vasco y trece del Parlamento catalán, todas ellas de entre las más importantes aprobadas en el período. En total, pues, han resultado afectadas un 20 por 100 de las leyes aprobadas, lo cual puede parecer excesivo si no se tienen en cuenta los factores de impreci-

\footnotetext{
${ }^{5}$ Véase una extensa argumentación en este sentido en $\mathrm{J}$. Salas, «Els poders normatius...», cit., págs. $131 \mathrm{y}$ sigs.
} 
sión en la delimitación competencial a los que se ha aludido anteriormente. Además, cabe señalar que 11 de las 25 leyes recurridas lo fueron en los primeros dieciocho meses de andadura autonómica, cuando aún las inseguridades y los tanteos predominaban sobre la prudencia y la cautela posterior. Del total de 25 recursos presentados por el Gobierno de Madrid contra otras tantas leyes autonómicas del País Vasco y Cataluña, 8 han sido presentados por el gobierno de Felipe González, es decir, con posterioridad al 28 de octubre de 1982. No parece que puedan plantearse, pues, grandes diferencias de criterio entre el período de gobiernos de UCD y el reciente período de gobierno socialista, aunque aún resulte prematuro esbozar conclusiones más o menos definitivas.

Con excepciones importantes, el Tribunal ha tendido a reconocer en sus sentencias la potestad legislativa de las Comunidades Autónomas, pero ha intervenido en todos aquellos artículos especíicos que significaban una vulneración de los principios recogidos en nuestra Constitución.

Resulta difícil concretar hasta qué punto toda la problemática externa a las Comunidades hasta ahora planteada (inconcreción del marco competencial, falta de legislación básica del Estado, temor a un excesivo desgaste por una reiteración de sentencias negativas del Tribunal Constitucional) ha podido resultar un grave condicionamiento en la iniciativa legislativa de los Gobiernos autonómicos del País Vasco y de Cataluña. Pero antes de establecer consideraciones más generales conviene analizar también factores internos a la propia Comunidad.

5. En el Parlamento de Cataluña hemos de empezar ya señalando las dificultades que plantea su propia composición:

\begin{tabular}{|c|c|c|}
\hline & 1980 & 1984 \\
\hline 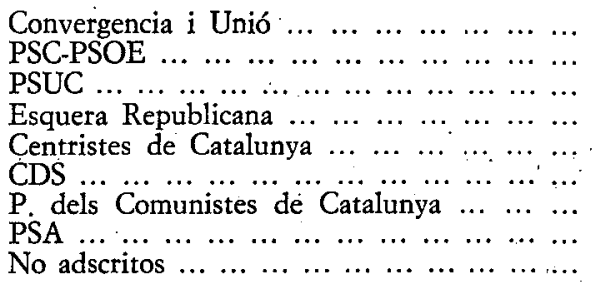 & $\begin{array}{l}43 \\
33 \\
23 \\
14 \\
18 \\
- \\
2 \\
2\end{array}$ & $\begin{array}{r}42 \\
31 \\
20 \\
13 \\
8 \\
6 \\
4 \\
\quad \quad 5\end{array}$ \\
\hline $\begin{array}{cccccc}\text { TOTAL } & \ldots & \ldots & \ldots & \ldots & \ldots\end{array}$ & 135 & 130 \\
\hline
\end{tabular}

Como puede observarse, a pesar de los cambios que los distintos avatares políticos (descomposición de UCD, surgimiento de CDS; escisión prosoviética en el PSUC, etc.), han provocado en la distribución de los dipútados, lo que no ha variado es la falta de mayoría absoluta parlamentaria de Convergencia i Unió, coalición que ocupa en solitario el Consejo Ejecutivo de la Generalidad. El gobierno minoritario de Jordi Pujol ha tenido, pues, que afrontar esos cuatro años de gestión en base a acuerdos puntuales y contrapartidas constantes con otros grupos de la Cámara; básicamente Esquerra Republicana y Centris- 
tas, antes; ahora, con Esquerra, el CDS y los diputados de AP-PDP, que se han mantenido formalmente en el grupo de Centristes. Como es notorio, ese conglomerado político oculta filosofías políticas y tradiciones muy distintas.

Centristes de Catalunya representaba, hasta el 28 de octubre de 1982, la opción del gobierno de UCD en Cataluña. Así la situación se contrapesaba, ya que los votos de la Minoría Catalana servían en Madrid para reforzar la falta de mayoría parlamentaria de la UCD, y en Cataluña eran los Centristes quienes apoyaban al gobierno de Convergencia. Hoy Centristes de Catalunya esconde un conjunto de 8 diputados conectados con Alianza Popular y el PDP. Al ir saliendo del Grupo los diputados que se unieron al CDS y otros que mantienen una situación de no adscripción teórica, aunque casi siempre votan con Convergencia, de hecho los restantes prefirieron mantenerse en el antiguo Grupo de Centristes y no engrosar un Grupo Mixto muy heterogéneo y con menos facilidades de intervención parlamentaria ${ }^{6}$.

Esquerra Republicana tiene sin duda mayores puntos de contacto con Convergencia, y, de hecho, el acuerdo político puntual entre ambos Grupos resulta más coherente que en el caso anterior. Ahora bien, la necesidad de diferenciación política se acentúa ante un compromiso electoral, y entonces Esquerra radicaliza su nacionalismo, sus connotaciones populistas y clama por una reforma del Estatuto que asegure mayor capacidad de autogobierno para Cataluña. En esos momentos, como ahora, se complica la situación y los acuerdos son más laboriosos y las contrapartidas más sustanciosas. La colaboración entre CiU y Esquerra se ha extendido a la participación de algunos miembros de Esquerra en la Administración autonómica; han presentado candidaturas conjuntas para el Senado, o Convergencia ha tenido que apoyar a Heribert Barrera, en su papel de presidente del Parlamento catalán, ante una moción de reprobación presentada precisamente por Centristes de Catalunya.

La situación en este final de Legislatura es aún más confusa, ya que la fragmentación centrista obliga a Convergencia a multiplicar los acuerdos bilaterales y, por tanto, las contrapartidas de toda índole con al menos cuatro grupos o corrientes distintas en el Parlamento: Esquerra, Centristes (APPDP), CDS y los diputados no adscritos, cuyo voto puede resultar decisivo en muchas ocasiones. A cambio de esos votos, Esquerra pidió que CiU apoyase en su propuesta de reforma del Estatuto catalán, o amenazó con no votar los Presupuestos para 1983 si se aceptaba la creación del Grupo Mixto ${ }^{7}$. Centristes (AP-PDP), por su parte, pidieron a $\mathrm{CiU}$ por su voto afirmativo en esos mismos Presupuestos de 1983, nada más y nada menos que un senador, de los siete que el Parlamento catalán puede enviar al Senado, un asesor personal

- El mes de junio de 1983 el Parlamento de Cataluña aprobó una ley elaborada en ponencia conjunta por todos los Grupos, por la que se modificaba el llamado Estatuto Interior y se creaba el Grupo Mixto. Hasta entonces sólo existían diputados no adscritos. Actualmente el Grupo Mixto del Parlamento de Cataluña es el cuarto Grupo de la Cámara, con 16 diputados: los del CDS, del PCC, el diputado del PSA y cinco diputados sin adscripción política determinada.

7 Esquerra Republicana se opuso con todas sus fuerzas a la creación del Grupo Mixto. De hecho, su posición era absolutamente minoritaria, pero, debido a sus presiones sobre $\mathrm{CiU}$, consiguió que el Grupo del gobierno votara en contra de la modificación reglamentaria, lo que tampoco puso en peligro la mayoría partidaria de la creación del Grupo Mixto. Véase Avui del día 16 de junio de 1983. 
de Pujol; la Presidencia de lós dos organismos de ayưda a la rèconversión industrial y tecnológica, que manejan fuertes sumas de dinero (CIRIT y CARIC), y hasta alguna jefatura territorial del gobierno de la Generalidad.

Lo importante, dejando a un lado esos meros ejemplos, es que esa alianza parlamentaria relativamente heterogénea actúa unida en las votaciones importantes y efectúa una labor de rodillo en temas como el presupuestario, donde, en los dos últimos años, apenas si se ha aprobado alguna enmienda socialista o comunista de las centenares presentadas por ambos. Grupos. Esa mayoría no está exenta de tensiones; tensiones que pueden llegar a provocar la pérdida por parte del Gobierno de algunas votaciones secundarias, sobre todo en el ámbito de las funciones parlamentarias de impulso y control. Pero esas tensiones tienen un más-importante reflejo en la actividad legislativa.

Las distintas orientaciones políticas de los Grupos que apoyan más o menos explícitamente al gobierno de Pujol ha sido un factor real de freno a la capacidad de iniciativa legislativa del gobierno y, por ende, a la misma capacidad legislativa del Parlamento de Cataluña. Leyes significativas, como la que preveía la disolución de las Cámaras Agrarias y la creación de Entidades Profesionales Agrarias o la ley de Normalización Lingüística, se han vistó bloqueadas durante meses y a veces han sido finalmente retiradas por el gobierno ante la imposibilidad de llegar a conciliar las distintas interpretaciones y exigencias de los integrantes de esa mayoría. La ley de división territorial de Cataluña, que implica-su comarcalización, anunciada desde el mismo inicio de la Legislatura; 'aün' no ha sido presentada, $\mathrm{y}$ en su retraso han sido determinantes las discrepancias 'sobre el tema de las fuerzas mencionadas, que, a pesar de estar de acuerdo en la comarcalización de Cataluña, no parecen estarlo en relación a las entidades supracomarcales, y sobre todo con las consecuencias electorales que se derivan de esa nueva división territorial.

En estos días se ha recordado que el Parlamento de Cataluña de 1932, en dos años y medio de actividad regular, aprobó 98 leyes, que globalmente podemös considerar mucho más importantes que las hasta ahora aprobadas por la actual Cámara legislativa catalana. Dejando a un lado las consideraciones relacionadas con la distinta estructura social, distinta concepción de la autonomía, distintas competencias y distinta concepción del Estado y de sus necesidades, lo cierto es que en aquel Parlamento, el Grupo de Esq́ierra Republicana contaba con una total hegemonía. Heribert Barrera, presidente del Parlamentó catalán actual y secretario general de Esquerra, decía hace poco: «Nuestro Parlamento se encuentra, a la hora de legislar, con una dificultad considerable en relación al de 1932, ya que aquella Cámara estaba constituida por una asamblea donde existía una mayoría formada por un solo partido $y$, por tanto, este partido podía acometer un programa de gobierno ý conseguir la aprobación rápida de sus proyectos, mientras que en nuestro Parlamento la situación es mucho más compleja; en cada caso es necesario encontrar las

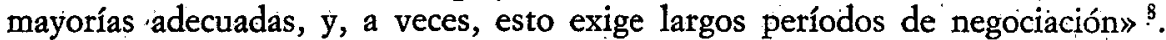

Si se examina la composición del Parlamento vasco, la situación es muy distinta:

8 Entrevista con Heribert Barrera en El País, edición dé Cataluña, 9 de diciembre de 1982. 


\begin{tabular}{|c|c|c|}
\hline & 1980 & 1984 \\
\hline 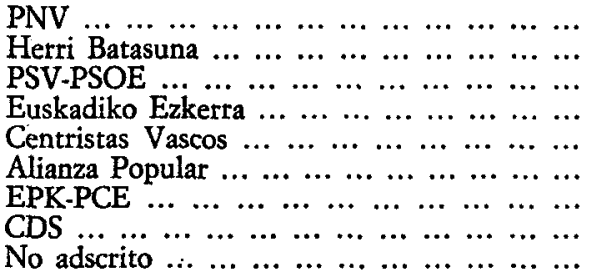 & $\begin{array}{r}25 \\
11 \\
9 \\
6 \\
6 \\
2 \\
1 \\
-\end{array}$ & $\begin{array}{r}25 \\
11 \\
8 \\
7 \\
2 \\
2 \\
4 \\
1\end{array}$ \\
\hline 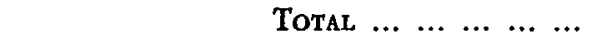 & 60 & 60 \\
\hline
\end{tabular}

Como puede verse, a pesar de los cambios producidos en los distintos Grupos, los nacionalistas vascos conservan la hegemonía, ya que debe recordarse que, desde el inicio de la Legislatura, los 11 diputados de Herri Batasuna han renunciado a estar presentes en el Parlamento. Con lo que, de hecho, de los 49 diputados presentes, el PNV cuenta con 25 diputados y, por tanto, tiene mayoría absoluta. Pero esa situación hegemónica no parece que haya provocado una mayor producción legislativa en comparación con su homónimo catalán, sobre todo si recordamos que un 40 por 100 de las leyes aprobadas por el Parlamento vasco tienen un contenido presupuestario o financiero a veces de alcance muy limitado. En este caso no pesa el factor ya comentado en relación con el Parlamento catalán de falta de mayoría parlamentaria, pero sí puede tener una cierta importancia la especial complejidad de la configuración territorial y política del PNV. Se ha definido al PNV como Partido-Comunidad, aludiendo a sus profundas raíces sociales, que desbordan el marco de una mera adscripción electoral. Pero su gran inserción social, su interclasismo, que es su fuerza fundamental, es al mismo tiempo el origen de todo tipo de tensiones. Tensión entre independentistas y partidarios de participar en las instituciones de ámbito autonómico y estatal; tensión entre conservadores y progresistas, y, sobre todo, por lo que hace referencia al presente ámbito de análisis, tensión entre el sector del partido que controla el gobierno vasco, y que defiende el «centralismo» de su actuación, y la corriente foralista, partidaria de defender la autonomía de los territorios históricos, es decir, su propia autonomía. Todo ello, que podría simplemente no tener trascendencia fuera del propio partido, se traslada a la actuación del gobierno y a su capacidad de iniciativa legislativa. Antes de presentar un proyecto de ley, el gobierno vasco se ve obligado a pactar su contenido con los distintos sectores ideológicos o territoriales del partido, si no quiere ver en entredicho su misma existencia.

Un ejemplo clamoroso y emblemático de lo dicho lo constituye la llamada ley de Territorios Históricos. En el programa legislativo del PNV se preveía la aprobación de esa ley en el cuarto trimestre de 1980. El primer proyecto del gobierno se presentó en junio de 1981 y no satisfizo a los sectores foralistas del PNV, que lograron que el Partido aconsejara, después de casi dos años de discusión, su retirada y la elaboración de un nuevo proyecto en el que se reducían las potestades de las Instituciones Comunes en favor de las Juntas Generales de los Territorios Históricos. Ese último proyecto, presentado en junio 
de 1983; fue, finalmente, aprobado a finales de noviembre de ese mismo año, ante la impotencia de los miembros del Gobierno?.

Existen, sin duda, otros factores que pueden introducirse al hacer un primer balance de la actividad legislativa de los Parlamentos vasco y catalán.

Se ha mencionado ya la indudable importancia de los Presupuestos. aprobados por ambos Parlamentos y el elevado número de funcionarios que dependen de ambas Administraciones autonómicas. No puede resultar extraño que las tareas de administración y gestión de los traspasos realizados, la creación de los servicios correspondientes, la estructuración de un cuerpo de Administración propio ha debido absorber la mayor parte de los esfuerzos de los ejecutivos vasco y catalán. Pero esa labor de gestión y adminiștración se ha ido fundamentando más en la legislación estatal, de viejo o nuevo cuño, que en la propia legalidad autonómica. No se ha querido o no se ha podido contraponer, en líneas generales, una legislación propia a la ya existente. Y partiendo de las razones ya expuestas, parece razonable pensar que ello también se ha debido a la simple aceptación de unas normas que se consideraban si: no plenamente' satisfactorias, sí funcionales.

Hace ya algunos meses se realizó una encuesta en el periódico Avui entre los portavoces de los cuatro Grupos Parlamentarios que no forman parte dé Gobierno, aunque alguno de ellos lo apoye en aras de la «gobernabilidad». En esa encuestra, que coincidía con los dos años de funcionamiento del Parlamento catalán, se insistía en lo que venimos afirmando. Así, Vicenç Capdevila, entonces portavoz de Centristas-UCD, decía: «Debe pasar en todos los gobiernos el que exista una cierta voluntad de actuar más por vía reglamentaria que no por la vía de someterse a las normas elaboradas por el legislativo. Nosotros vemos cómo el Consejo. Ejecutivo ha asumido muchos traspasos de servicios, y io primero que debiera haber hecho era promover la iniciativa legislativa para actualizar la legislación estatal, que regulaba hasta aquel momento los servicios transferidos.» Joan Hortalà, portavoz de Esquerra Republicana, decía después de referirse a la falta de iniciativa legislativa del gobierno de $\mathrm{CiU}$ : «Parece que al gobierno de la Generalidad le conviniera más ir gobernando sin un marco definido, moviéndose en la ambigüedad.» Eduardo Martín Toval, entonces portavoz socialista, era más tajante: «En las actuales circunstancias, el Parlamento no es la expresión fundamental del autogobierno catalán. La Generalidad actual es poco legislativa y poco parlamentaria. La gran contradicción de Convergencia es que, llamándose partido nacionalista y gobernando en Cataluña, es quien da menos importancia al Parlamento. Una Generalidad con simple poder ejecutivo podríamos tenerla con una Mancomunidad de Diputaciones.» Finalmente, la opinión de Rafael Ribó, portavoz del PSUC: «Sin tapujos, tenemos un Consejo Ejecutivo y un presidente de la Generalidad que se han puesto como objetivo hacer de la autonomía una macrodiputación. Se quieren dedicar a una tarea de administración, de gestión, sin utilizar su poder de tomar decisiones políticas autónomamente; están coordinando lo que se les ha traspa-

9 El ex portavoz del PNV en el Parlamento vasco y ex diputado general de Alava, Emilio Guevara, fue el auténtico protagonista de esta ley. Consiguió que se retirara el proyecto del Gobierno por una apretadísima votación en el seno del Grupo Parlamentario Nacionalista y posteriormente convenció a una asamblea general del PNV de la necesidad de apoyar un nuevo proyecto que reforzaba las instituciones forales. 
sado de las delegaciones ministeriales. El Consejo Ejecutivo no quiere ni puede profundizar en los mecanismos de autogobierno, y, en primer lugar, por la vía legislativa del Parlamento, para abordar los grandes problemas.» Como vemos, las opiniones coinciden, con más o menos matices críticos, tanto en los partidos de clara oposición al gobierno de Jordi Pujol como en aquellos otros partidos que colaboraban y colaboran en su mantenimiento.

Es, en definitiva, la constatación de que se ha avanzado poco en la creación de una legalidad propia, que refleje la institucionalización de la autonomía, del auto nomos. Después de los primeros problemas con el Tribunal Constitucional, el gobierno de la Generalidad pareció encerrarse en el ámbito de la gestión y administración, en el «hacer cosas», y sólo algún departamento como el de Política Territorial y Obras Públicas presenta y logra aprobar leyes como la de Protección de la Legalidad Urbanística o las de Protección de Espacios Naturales, que demuestran que sí es posible legislar, ya que, a pesar de que algunas fueran impugnadas por el Gobierno central, su motivación no es aceptada por el Tribunal Constitucional. La falta de confianza sobre la propia capacidad técnica y jurídica (el grupo del gobierno ha remitido al Consejo Consultivo siete leyes ante las dudas surgidas en su discusión) ${ }^{10}$, las previsibles dificultades que la falta de mayoría parlamentaria plantea y, cómo no, las restricciones y recelos que constantemente parecen surgir de «Madrid» han ido afectando al gobierno de CiU en su iniciativa legislativa. La hegemonía socialista en Madrid y, por tanto, el hecho de que los votos de la Minoría Catalana no sean decisivos en las Cortes, como lo habían sido, ha propiciado también una sensación de cerco, de política defensiva frente a los peligros de agresión, de «laminación» de la autonomía, a lo que tampoco son ajenas las poco afortunadas intervenciones de algunos dirigentes estatales de vez en cuando.

Sólo la proximidad de las elecciones autonómicas ha acelerado el ritmo de presentación de proyectos legislativos por parte del gobierno y, en consecuencia, ha aumentado también el número de leyes aprobadas. Hemos de tener en cuenta que entre marzo de 1980 a finales de diciembre de 1982 el gobierno de $\mathrm{CiU}$ llegó a presentar un total de 44 proyectos de ley, y, en cambio, son ya 39 los proyectos presentados a finales de 1983. La cercanía de la contienda electoral, una mayor experiencia y seguridad técnica y la voluntad de que el balance general de estos cuatro años sea lo más positivo posible ha lanzado a todas las Consejerías de la Generalidad a acelerar ritmos y a presentar tantos proyectos de ley como en los tres años anteriores. También el ritmo de aprobación de las leyes se ha incrementado, y si entre 1980 y 1982 se aprobaron 35 leyes, en 1983 han sido 26 las aprobadas.

Pero, a pesar de este acelerón legislativo en el último tramo de la legislatura, el Parlamento de Cataluña se ha caracterizado, en estos cuatro años, sobre todo como centro de debate político de la Comunidad catalana. Con alguna excepción, los líderes políticos más destacados han estado presentes en sus

${ }^{10}$ El Consejo Consultivo de la Generalidad, cuya creación estaba contemplada en el Estatuto, empezó a funcionar en 1981 y tiene como misión examinar la adecuación al Estatuto catalán de cuantos proyectos o proposiciones de ley le sean sometidos tras la petición de dos Grupos Parlamentarios, una décima parte de los diputados o el Consejo Ejecutivo. 
escaños, y ello ha propiciado que los medios de comunicación se ocupen del Parlamento y de sus debates, y: así la opinión pública se ha acercado a alguna de sus sesiones más polémicas. Esa función de mediación, de negociación política, ha venido acompañada de una cierta capacidad de impulso y control de la actuación del gobierno, sobre todo en materia de administración de competencias, y en una constante exigencia de una mayor intervención del ejecutivo catalán en los temas más acuciantes de la sociedad catalana, y de manera especial en el paro. El cerca de un centenar de resoluciones aprobadas por el Pleno como resultado de los debates celebrados (resoluciones donde encontraríamos el origen de muchos de los proyectos presentados con posterioridad por el gobierno), las 120 proposiciones. no de ley, las 190 interpelaciones o las casi 900 preguntas formuladas así lo demuestran. Ha sido, pues, un Parlamento activo, que ha funcionado notablemente bien, con una organización interna eficaz y una buena imagen exterior, pero cuya resultante legislativa ha sufrido los condicionantes mencionados.

El Parlamento vasco ha tenido en estos años una colocación institucional distinta a la de su homónimo catalán. Hemos ya mencionado la especial configuración del partido en el gobierno como Partido-Comunidad. Su heterogeneidad ideológica y social encuentra su elemento unificador y cohesionador en su concepción del presidente de la Comunidad, el lehendakari, que personaliza el gobierno, la unidad del partido y, en definitiva, se convierte en símbolo de la Comunidad. Los elementos presidencialistas de la ley de Gobierno, aprobada por el Parlamento vasco, han sido señalados repetidamente. Se afirmaba en un estudio reciente: «La unidad del pueblo se refleja en el partido político que, a su vez, proyecta dicho carácter en el nivel institucional. El principio unitario se eleva, por medio de diversos trámites, desde el orden social al ámbito jurídico, en una coordinación perfecta que todo lo envuelve» ". En ese organigrama, en esa concepción institucional, el Parlamento no acaba de encajar claramente. Recordemos que en el Estatuto no se dice explícitamente que el Parlamento representa al pueblo. Si el Partido-Comunidad mantine en el mismo una posición hegemónica, puede tender a prescindir de la Cámara o, para ser más exactos, a utilizarla en lo imprescindible: Si además una formación política que representa una significativa porción del electorado, y que constituye el segundo Grupo de la Cámara, no acepta el marco institucional definido en la Constitución y en el Estatuto, y apoya con más o menos claridad opciones de oposición violenta al régimen legalmente constituido, entenderemos por qué el Parlamento vasco presenta al final de su primera Legislatura un balance menos completo que el del Parlamento de Cataluña. Se ha aprobado 60 leyes, pero de ellas el 40 por 100 tienen un contenido presupuestario o financiero y además más de la mitad ( 31 para ser precisos) han sido aprobadas en el año 1983, probablemente por las mismas razones apuntadas para explicar el acelerón legislativo final en Cataluña. Pero es que, además, el balance de la actividad de impulso y control no alcanza el nivel de la Cámara catalana. Cerca del centenar de proposiciones no de ley, otras tantas interpelaciones y alrededor de trescientas preguntas es el resumen cuantitativo final.

${ }^{11}$ M. A. García Herrera, «Consideraciones en torno a la forma de gobierno de la Comunidad Autónoma vasca», en Revista Vasca de Administración Pública, núm. 2, Oñate, enero-abril 1982. 
Debemos también señalar un hecho que puede resultar significativo. Cerca de una quincena de parlamentarios han renunciado a su escaño, siendo sustituidos por otros miembros de su partido o coalición, y esto en un Parlamento de 49 miembros efectivos es una proporción notable. Entre esas renuncias encontramos las de políticos vascos tan significativos como Oreja Aguirre, Roberto Lertxundi, Mario Onaindía, Txiki Benegas, Jesús $M^{a}{ }^{a}$ de Leizaola o García Damborenea. El Grupo de Socialistas Vascos ha cambiado totalmente su composición desde la formación del Parlamento. En definitiva, no parece que la clase política vasca conceda a su Cámara legislativa una atención preferentemente, lo que sin duda indica una cierta situación de marginalidad del Parlamento en el complejo acontecer político del País Vasco. Por otra parte, la Cámara no ha contado con un Reglamento definitivo hasta entrado el año 1983; no dispone de un Estatuto de Régimen Interior que fije la organización y reglamento de los servicios parlamentarios; y sus publicaciones no presentan las facilidades de seguimiento de la actividad parlamentaria que serían deseables.

Así, el Parlamento vasco presenta una cierta situación de marginalidad en la vida política comunitaria. Ausentes los principales líderes, sin la presencia de la segunda fuerza parlamentaria, y bajo el predominio de un partido que tiene canales mucho más eficaces y directos de conexión con la sociedad, el Parlamento no pasa de ser una institución formalmente necesaria, pero con poca proyección pública. La aprobación de la ley de Territorios Históricos puede agravar esa situación, al pasar buena parte de las competencias de las Instituciones comunes a las Juntas Generales de las distintas provincias y dotando a esas mismas Juntas de poderes normativos en su esfera competencial.

6. Algunas conclusiones: El profesor García de Enterría, en una de las abundantes citas que recoge en sus trabajos, reproduce una frase del juez Holmes: «La vida del Derecho no es la lógica, es la experiencia.» La experiencia de los Parlamentos vasco y catalán en estos casi cuatro años de actividad ha tenido una resultante legislativa problemática y hasta cierto punto limitada. Con lo hasta aquí expuesto se ha pretendido encontrar algunas razones qui: explicaran esa situación y posibilitaran reflexionar sobre el binomio autonomiacuerpo legislativo propio, o también autogobierno-capacidad legislativa. Podríamos resumir lo hasta aquí expuesto en una serie de puntos:

a) Los Parlamentos vasco y catalán han aprobado, en estos casi cuatro añọs, alrededor de 120 leyes, de las cuales sólo algunas tienen una entidad y trascendencia material importante, mientras que muchas de ellas son de carácter autoorganizativo, de contenido presupuestario o financiero, o de alcance muy limitado.

b) Las razones que pueden explicar ese balance son tanto de orden externo a las propias Comunidades como de orden interno a las mismas.

c) Entre las de orden externo cabe destacar la aún no clara delimitación competencial entre el Estado y las Comunidades Autónomas; la falta de legislación de bases del Estado; las resistencias del Gobierno central; sus recursos ante el Tribunal Constitucional, que ha provocado una actitud cautelar, tanto técnica como políticamente, en la iniciativa legislativa de los Gobiernos vasco y catalán, preocupados ante el desgaste político derivado de una conflictividad permanente. 
d) Entre las de orden interno destacan: la falta de mayoría parlamentaria del gobierno de $\mathrm{CiU}$ en Cataluña; las contradicciones internas del PNV en el País Vasco; la dedicación prioritaria de los Gobiernos autonómicos a la gestión y administración de los servicios traspasados y a la creación de una administración propia; la no conflictividad con las leyes estatales existentes, que regulan las materias traspasadas, y la aceptación de su funcionalidad.

e) Los Parlamentos vasco y catalán, durante este período, han desarrollado otro tipo de actividades. El Parlamento catalán se ha consolidado como Cámara deliberante y de control. Ha desarrollado una importante actividad de debate $y$ ha usado ampliamente de los instrumentos de impulso y control de la actividad de gobierno. Ha logrado mantener también una notable presencia en los medios de información y, en general, se presenta permeable a lọ grandes temas de interés de la opinión pública.

El Parlamento vasco, que, de hecho, ha quedado reducido a 49 parlamentarios efectivos por la ausencia del Grupo de Herri Batasuna, ha tenido una actividad más reducida que la Cámara catalana, no tanto en el número de leyes aprobadas como sobre todo en la entidad de sus funciones de impulso y control de la actividad del Gobierno. Su posición institucional no se ha correspondido con su real incidencia en el proceso y la dinámica política del País Vasco.

En fin, aún resulta prematuro establecer conclusiones definitivas sobre un proceso que, de hecho, apenas si ha empezado. La resolución final sobre la LOAPA ha desechado por ahora la vía de una ley globalizadora y en buena parte uniformizadora de las Comunidades Autónomas y sus competencias. La vía que el Tribunal Constitucional ha marcado en sus sentencias es, sin duda, más respetuosa con la voluntad de los constituyentes, pero al mismo tiempo es una vía más lenta y cargada de conflictividad $y$, por tanto, puede retardar las posibilidades de establecer un balance global sobre las autonomías. Ahora bien, si quisiéramos avanzar algunas perspectivas a partir de lo hasta aquí expuesto, podríamos afirmar lo siguiente: el elemento característico de la autonomía política, es decir, el poder de determinar una autónoma orientación, no se produce sólo por cauces legislativos, sino que se concreta en diversas vías. Son así diferentes manifestaciones de la autonomía política: la autonomía legislativa, la autonomía estatutaria, la autonomía financiera, la autonomía administrativa y también un autónoma manera y capacidad de mediar, de servir de cauce a los intereses específicos de la Comunidad sobre la que se asienta la propia esfera de autopoder. Así pueden verse acrecentadas las posibilidades y la influencia de los Parlamentos autonómicos por la vía de servir de cauce de mediación entre los diversos sectores de la propia Comunidad, mediación entre fuerzas políticas que de alguna manera representan esos sectores, mediación y cooperación, en fin, entre la propia Comunidad y el Estado. Dentro de esa perspectiva de plasmación técnica y jurídica de esos compromisos parece mejor situado funcional e institucionalmente el Parlamento catalán que el vasco, aunque la falta de una fuerza política mayoritaria y coherente debilite sus posibilidades de proyección. 